Supplement of Earth Syst. Dynam., 11, 35-76, 2020

https://doi.org/10.5194/esd-11-35-2020-supplement

(C) Author(s) 2020. This work is distributed under

the Creative Commons Attribution 4.0 License.

(c) (1)
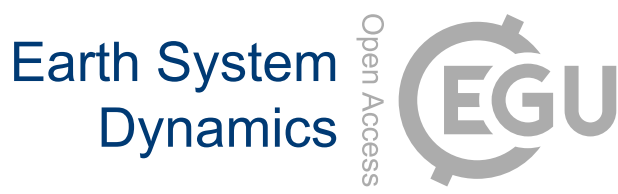

Supplement of

\title{
Projecting Antarctica's contribution to future sea level rise from basal ice shelf melt using linear response functions of 16 ice sheet models (LARMIP-2)
}

Anders Levermann et al.

Correspondence to: Anders Levermann (anders.levermann@ pik-potsdam.de)

The copyright of individual parts of the supplement might differ from the CC BY 4.0 License. 

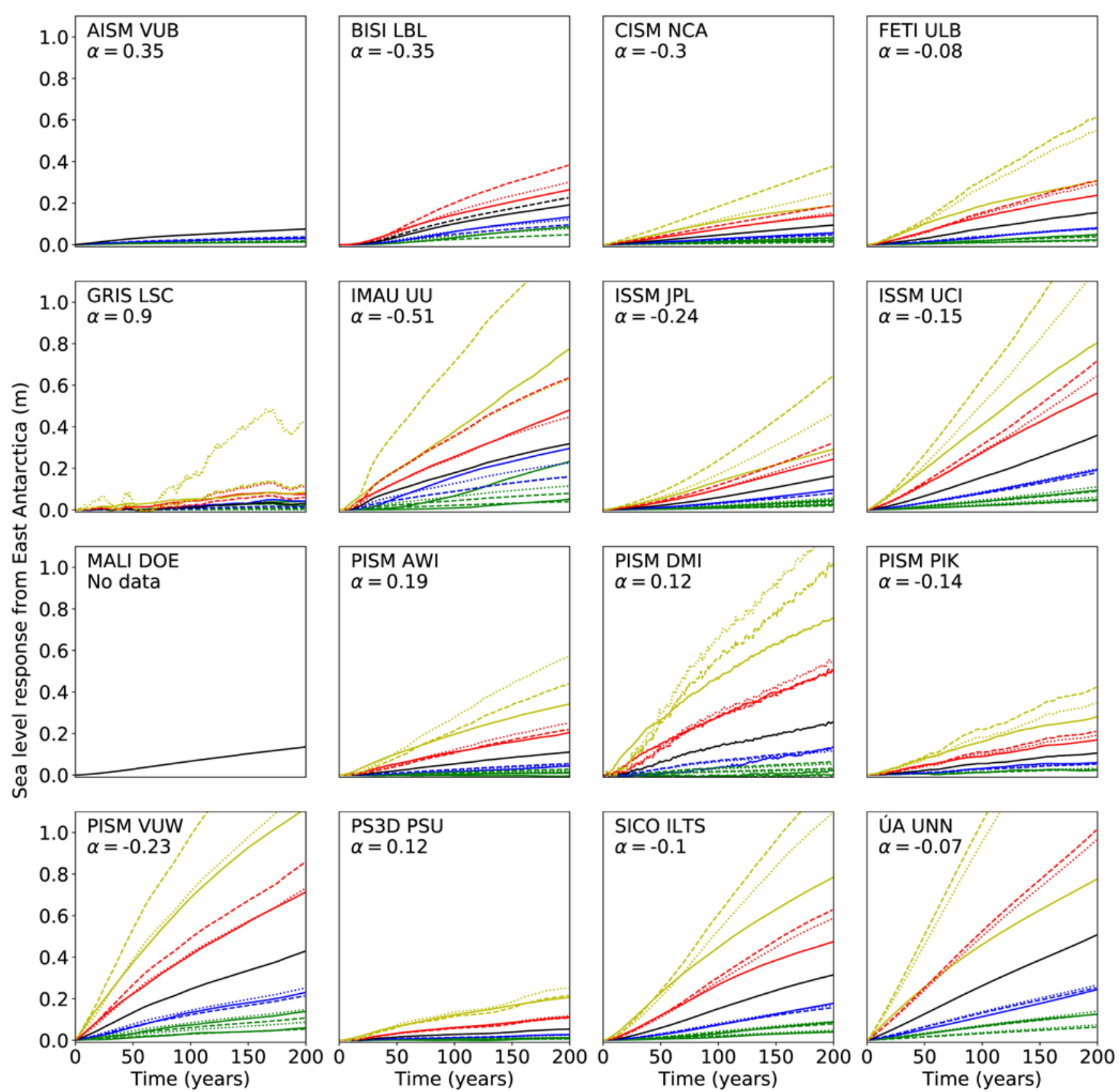

Figure S1a: Linearity check for East Antarctica as in Figure 4 but including the simulations with 2 m/yr (green) and 32 $\mathrm{m} / \mathrm{yr}$ (yellow) of additional basal melting. 

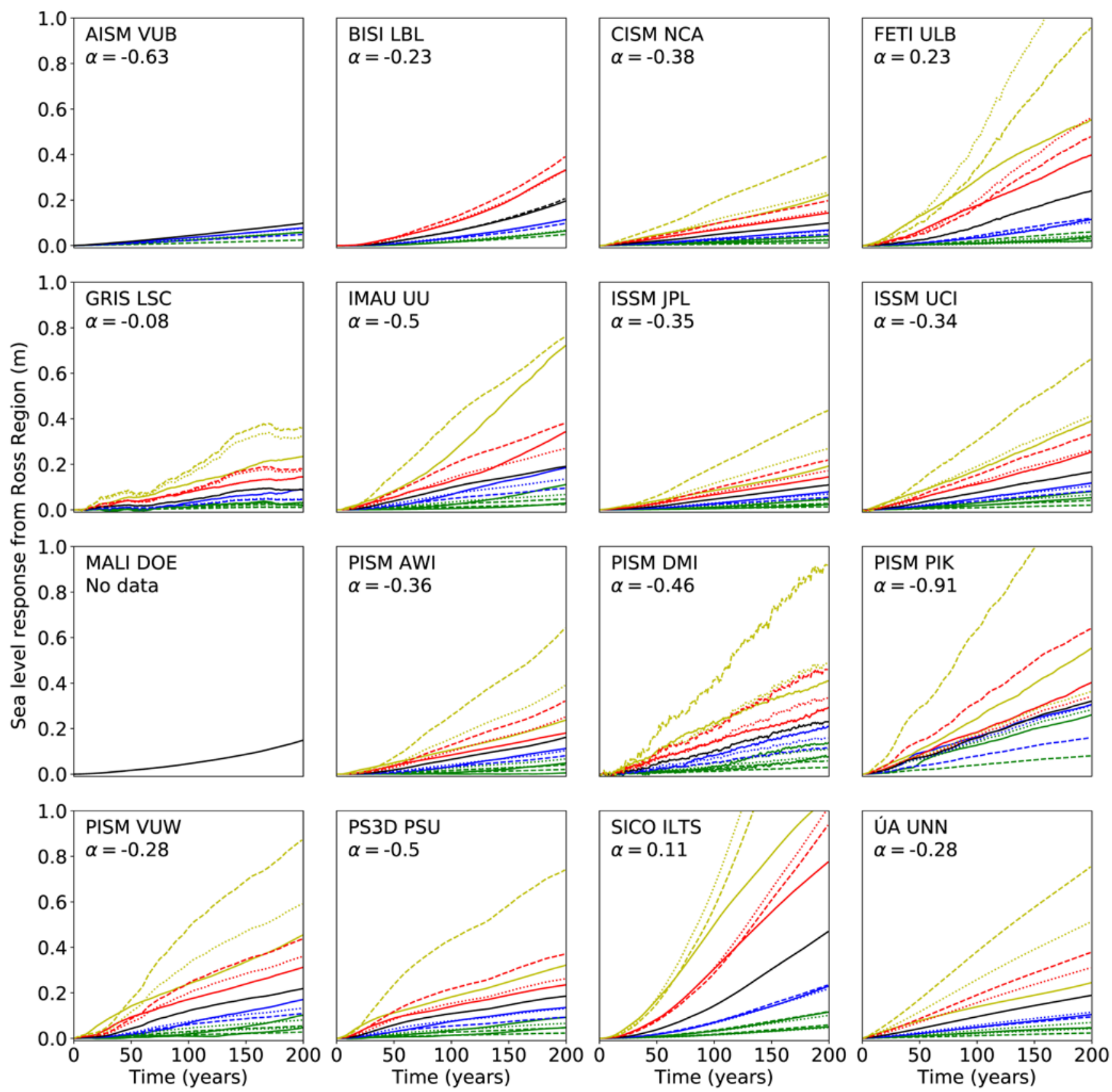

Figure S1b: Linearity check for the Ross region as in Figure S1a. 

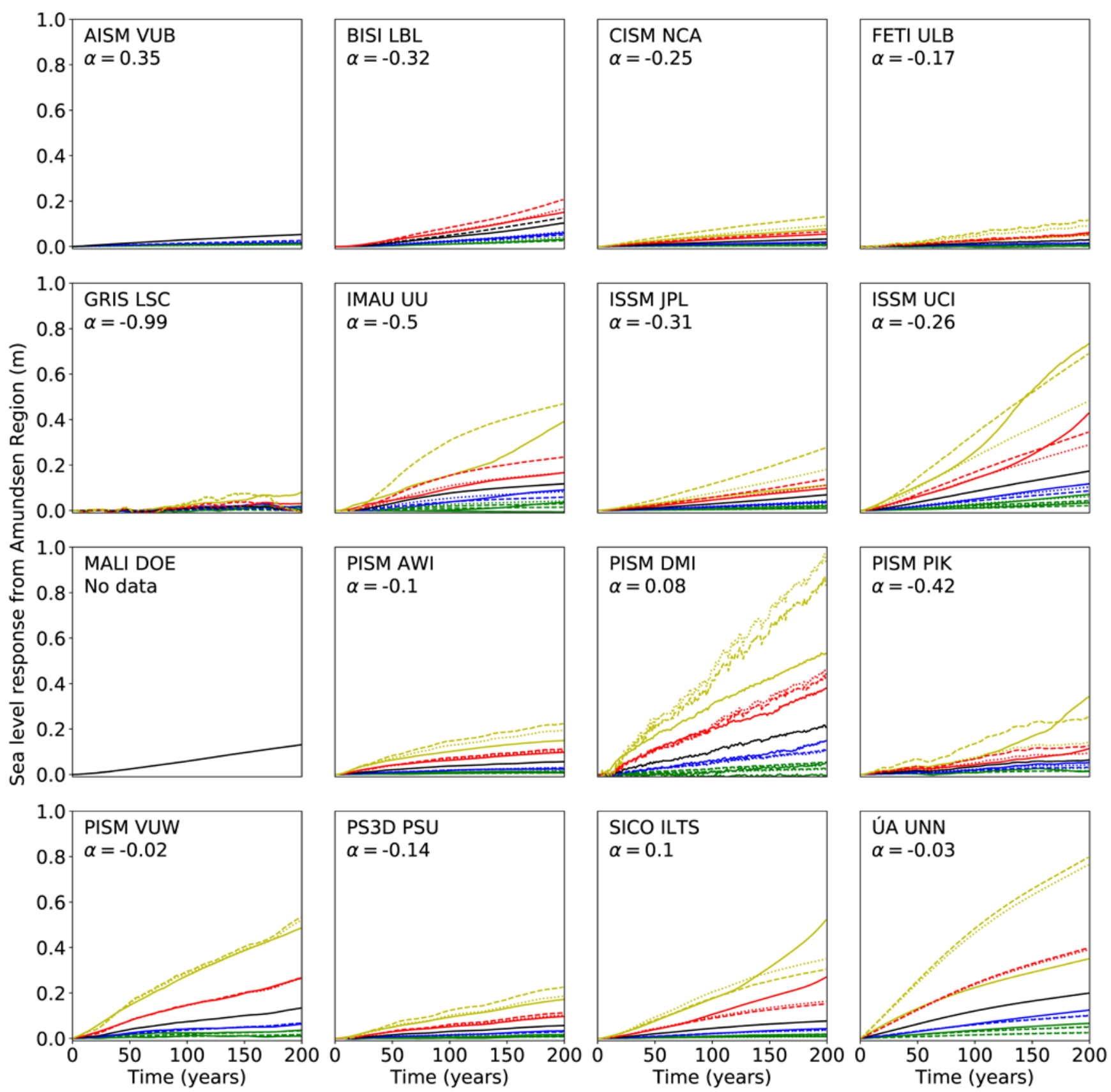

Figure S1c: Linearity check for the Amundsen region as in Figure S1a. 

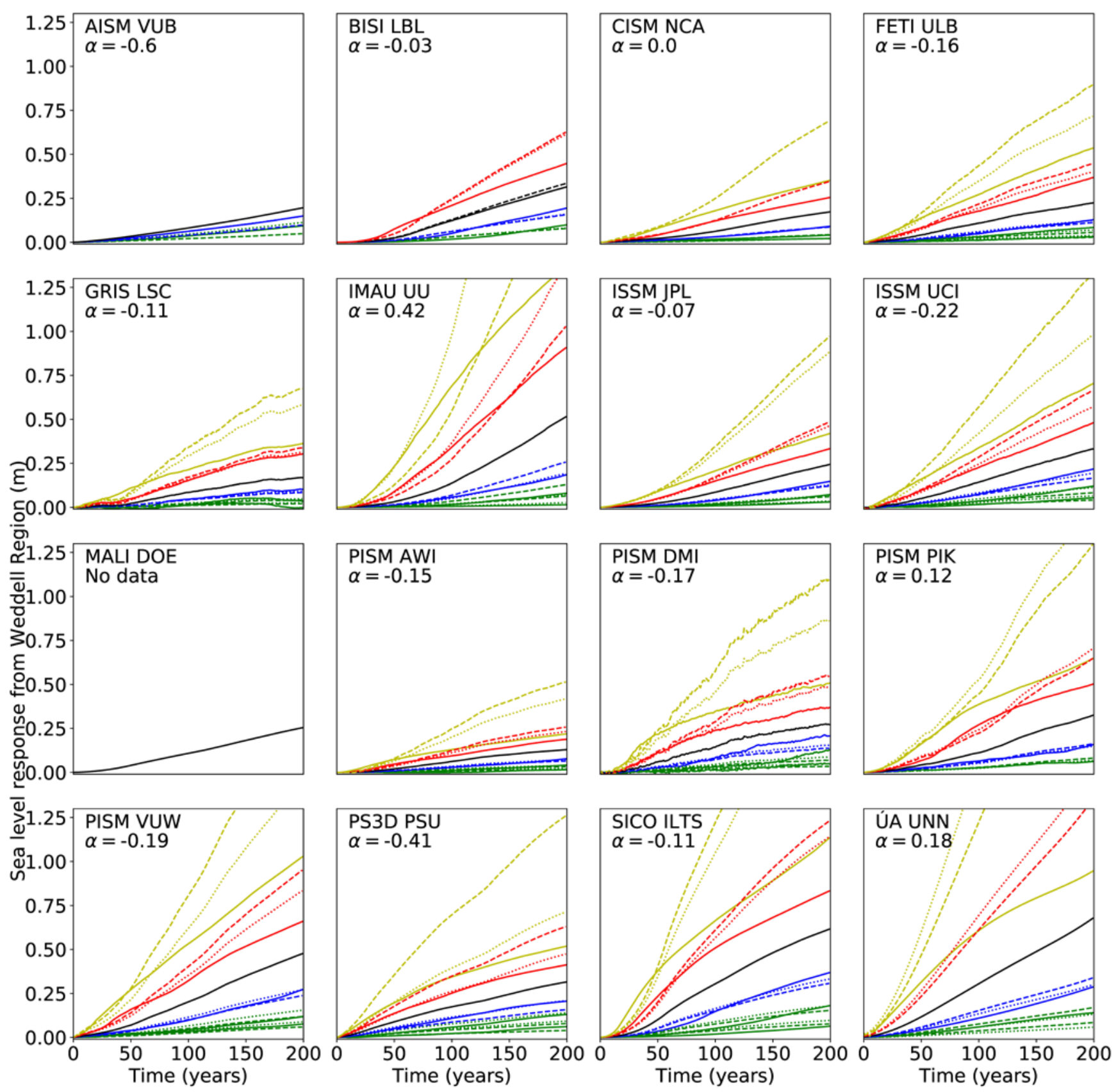

Figure S1d: Linearity check for the Weddell region as in Figure S1a. 

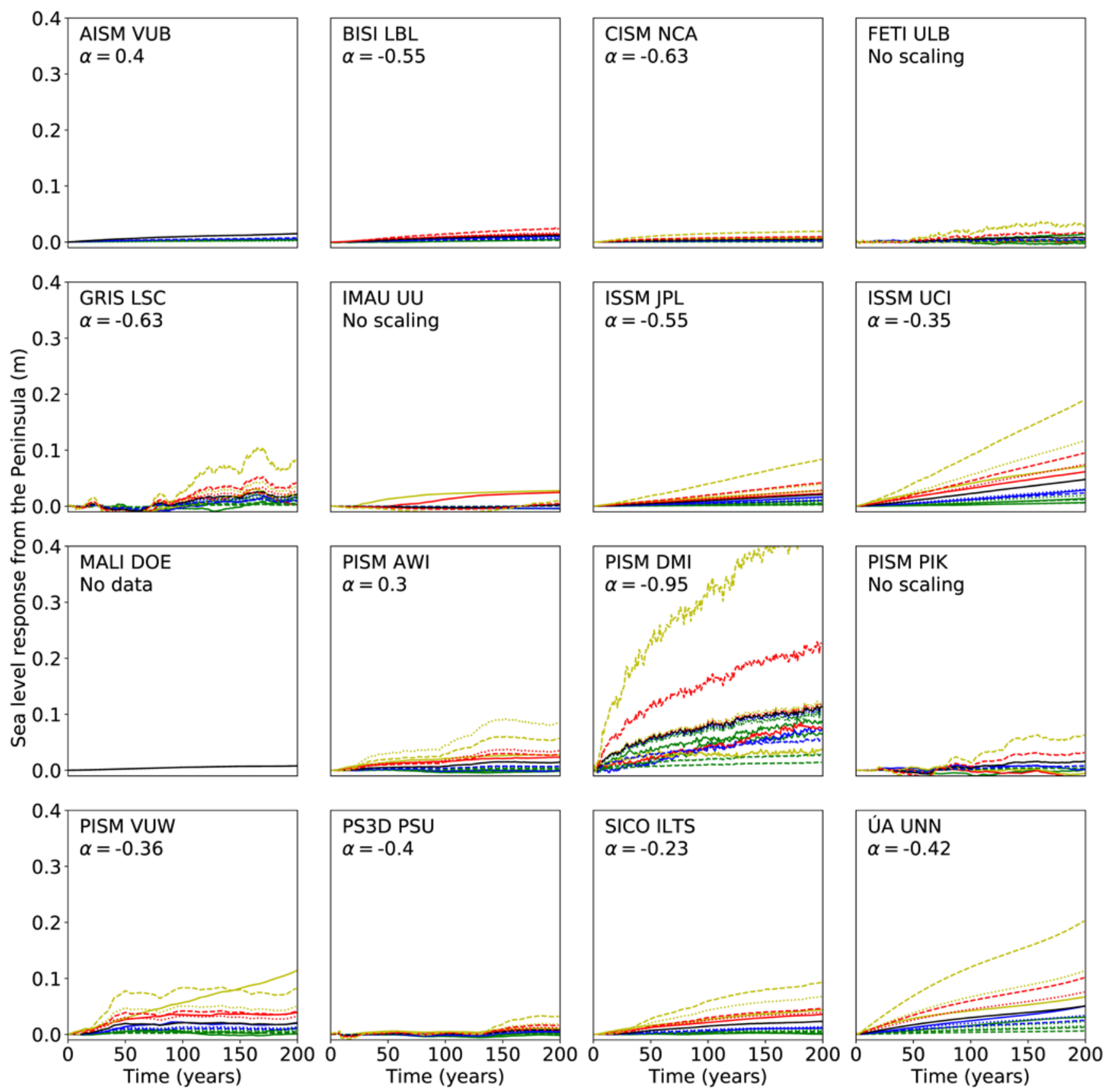

Figure S1e: Linearity check for the Antarctic Peninsula as in Figure S1a. 
